\title{
Simultaneous determination of $\beta$-agonists and monitoring in bovine tissues by liquid chromatography-tandem mass spectrometry
}

\author{
Kyunghun Jeong ${ }^{1}$, Md Akil Hossain ${ }^{1}$, Hae-chul Park ${ }^{1}$, Seong-Wan Son², JeongWoo Kang ${ }^{1}$ \\ ${ }^{1}$ Veterinary Drugs \& Biologics Division, Animal and Plant Quarantine Agency (APQA), \\ Gimcheon 177, Republic of Korea \\ ${ }^{2}$ Ministry of Food and Drug Safety, Osong Health Technology Administration Complex, \\ Cheongju, Republic of Korea \\ Received January 31, 2017 \\ Accepted April 3, 2018
}

\begin{abstract}
The misuse of $\beta$-agonists leads to a potential risk to public health and is forbidden in many countries. We developed a rapid, sensitive and reliable multi-residue detection method for zilpaterol, ractopamine, and clenbuterol in bovine tissues by liquid chromatography-tandem mass spectrometry. Residues were extracted in ethyl acetate after protein precipitation, and then analyzed by the developed method. Good linearities $\left(\mathrm{R}^{2}>0.99\right)$ were observed, and the recoveries of zilpaterol, ractopamine, and clenbuterol were $99 \%, 74 \%$, and $102 \%$, respectively. The limits of quantitation for zilpaterol, ractopamine, and clenbuterol were 1.3, 5.0, and $1.7 \mathrm{ng} / \mathrm{g}$, respectively. The method is also applied successfully to bovine tissues within the Korean National Residue Programme. None of the $3 \beta$-agonists were detected from 50 domestic samples. However, zilpaterol $(6.3 \mathrm{ng} / \mathrm{g})$ was quantified in one out of the 50 imported samples. The application of this method will be helpful in quality control analysis of $\beta$-agonists residues in bovine tissues.
\end{abstract}

Multi-residue detection, zilpaterol, ractopamine, clenbuterol, LC-MS/MS

Beta-agonists are a group of synthetic compounds which are used in human and veterinary medicine for the treatment of lung diseases as bronchodilators and heart tonics. Besides their original use, these drugs are often misused as growth promoters, to improve carcass composition by decreasing fat to the benefit of muscle mass (Anderson et al. 2009). At higher doses, an anabolic growth-promoting effect is evidenced with increased muscle development and reduced fat deposition. These effects lead to the misuse of these drugs in livestock production. Moreover, the use of $\beta$-agonists as feed additives for livestock has progressively forwarded at doses above therapeutic ones (Bocca et al. 2003).

Excessive use of $\beta$-agonists leads to the accumulation in animal tissues. High amounts of $\beta$-agonist residues posec potential risk to human health, such as central nervous and heart disorders (Martinez-Navarro et al. 1990). Therefore, the use of $\beta$-agonists as growth promoters has been banned by the Commission of the European Communities (European Commission 1996). However, these drugs (Fig. 1) including zilpaterol, ractopamine and clenbuterol are still used illegally. Clenbuterol was the main $\beta$-agonist substance used illegally for this purpose. But other $\beta$-agonist substances have been developed to be used for zoo-technical purposes, such as ractopamine, licensed for this application in the United States and currently zilpaterol, licensed in South Africa (Anderson et al. 2009). However, these compounds are banned in the European Union (EU). Thus, the determination of these drugs' residues in animal tissues is very important for health.

During the last few years, several analytical approaches have been used for the detection of $\beta$-agonists with different techniques. Screening methods based on enzyme immunoassay (EIA) (Degand et al. 1993) and enzyme-linked immunosorbent assay

Address for correspondence:

JeongWoo Kang

Veterinary drugs \& Biologics Division

Animal and Plant Quarantine Agency (APQA)

Gimcheon 177, Republic of Korea 
<smiles>CC(C)N[C@H]1CCn2c(=O)[nH]c3cccc(c32)[C@H]1O</smiles>

(A)<smiles>CC(CCc1ccc(O)cc1)CNC(O)c1ccc(O)cc1</smiles>

(B)<smiles>CC(C)(C)NC[C@H](O)c1cc(Cl)c(N)c(Cl)c1</smiles>

(C)

Fig. 1. Chemical structures of three $\beta$-agonists those are analysed in this study. (A) zilpaterol, (B) ractopamine, and $(\mathrm{C})$ clenbuterol.

(ELISA) kits (Angeletti et al. 1993) have been performed for the detection of illegal use. But, immunoassay techniques can only be applicable in the detection of a single $\beta$-agonist compound or a group of $\beta$-agonists with similar chemical structure. It was reported that the matrix has a great interference in the detection of $\beta$-agonists. Liquid chromatography (LC) methods coupled with different detection systems such as ultraviolet (UV) (Yan et al. 2016) and diode array detector (DAD) (Blomgren et al. 2002) were developed earlier. Although, according to the Commission Decision 2002/657/EC (European Commission 2002), the confirmation of the presence of an analyte by means of liquid chromatography coupled to diode array detector (LC-DAD) or liquid chromatography coupled to electrochemical detector (LC-ED) alone is not sufficient (European Commission 2002). So, confirmation methods have mainly been performed with gas chromatography-mass spectrometry (GC-MS) or tandem mass spectrometry (GC-MS/MS) (Batjoens et. al 1996). Recently, application of liquid chromatography-mass spectrometry (LC-MS) has been reported (Antignac et al. 2002). Most of the current extraction methods are time consuming, tedious and complex. Solid-phase extraction (SPE) which is a method for separating desired compounds and impurities from mixtures based on their physical and chemical properties (Wang et al. 2013) is widely used for extraction and purification. However, the recovery rates of drug substances by solid phase extraction (SPE) are comparatively low as reported in a previously published article (69-79\%) (Kulikovskii et al. 2016). Additionally, the general SPE clean-up techniques lack of specificity and selectivity, and can mix analytes and interferents. This leads to interference, reducing the reliability of determination. Due to these reasons; more developments in the detection methods of these $\beta$-agonists are required for the rapid and specific determination.

Thus, the aim of this study was to develop a rapid, sensitive, specific and reliable analytical multi-residue method for the confirmation of the presence or absence of zilpaterol, ractopamine, and clenbuterol residues in bovine tissues by LC-MS/MS. The method was validated and successfully applied within the residue surveillance programme. 


\section{Materials and Methods}

\section{Chemical and reagents}

The reagents used in this study were of the LC grade. Zilpaterol and zilpaterol D-7 were purchased from the Toronto Research Chemicals (TRC, Toronto, Ontario, Canada). Ractopamine and clenbuterol were purchased from Sigma-Aldrich (St. Louis, MO, USA), and clenbuterol D-9 was fom Witega Laboratorien Berlin-Adlershof, $\mathrm{GmbH}$ (Berlin, Germany). Fresh ultrapure water was obtained from a Milli-Q Integral System equipped with a $0.22 \mu \mathrm{m}$ Millipak membrane point-of-use cartridge (EMD Millipore, Billerica, MA, USA).

\section{Instrumentation and chromatographic conditions}

Analyses were performed using the Quattro micro triple quadrupole analyser (Micromass, Manchester, UK), with a YMC pack $\mathrm{C}_{18}$ column $(2.0 \times 100 \mathrm{~mm}, 3 \mu \mathrm{m})$. The mobile phase was a mixture of (A) $0.1 \%$ formic acid in distilled water and (B) $0.1 \%$ formic acid in acetonitrile, where the ratio of " $\mathrm{A}$ " and " $\mathrm{B}$ " were different, and maintained in a gradient flow. The gradient flow started with $1 \% \mathrm{~B}$ and increased to $100 \%$ in 5.5 min, stayed at $100 \%$ up to $7.0 \mathrm{~min}$, and then returned to the initial composition within $10.0 \mathrm{~min}$. The flow rate was $0.3 \mathrm{ml} / \mathrm{min}$, and the injection volume was $5 \mu$ l. Positive electrospray ionization (ESI) was utilized and the mass spectrometer was operated in multiple reaction monitoring (MRM) mode as listed in Table 1.

Table 1. Chromatographic conditions used in the detection and quantitation of three $\beta$-agonists residues in bovine tissues by tandem mass spectrometry (MS/MS).

\begin{tabular}{lccccc}
\hline Compound & Polarity & $\begin{array}{c}\text { Precursor } \\
\text { ion }(\mathrm{m} / \mathrm{z})\end{array}$ & $\begin{array}{c}\text { Product } \\
\text { ion }(\mathrm{m} / \mathrm{z})\end{array}$ & $\begin{array}{c}\text { Cone } \\
\text { voltage }(\mathrm{V})\end{array}$ & $\begin{array}{c}\text { Collision } \\
\text { energy }(\mathrm{eV})\end{array}$ \\
\hline \multirow{2}{*}{ Clenbuterol } & \multirow{2}{*}{ Positive } & 277.00 & 202.90 & 22 & 18 \\
\hline \multirow{2}{*}{ Clenbuterol-d9 } & \multirow{2}{*}{ Positive } & 286.10 & 259.00 & 22 & 10 \\
\hline \multirow{2}{*}{ Zilpaterol } & \multirow{2}{*}{ Positive } & 262.10 & 244.17 & 25 & 18 \\
\hline \multirow{2}{*}{ Zilpaterol-d7 } & \multirow{2}{*}{ Positive } & 244.07 & 185.00 & 22 & 15 \\
\hline \multirow{2}{*}{ Ractopamine } & \multirow{2}{*}{ Positive } & 269.16 & 251.14 & 24 & 15 \\
& & 251.14 & 185.00 & 40 & 24 \\
\hline
\end{tabular}

Preparation of standard solutions

All the individual and composite standard stock solutions were prepared in methanol. A series of drug solutions at a concentration ranging from 0 to $500 \mathrm{ng} / \mathrm{ml}$ were prepared. The drug solutions with desired concentrations were prepared by diluting the stock solution $(100 \mathrm{mg} / \mathrm{ml})$ with the mobile phase. The solutions were filtered through a $0.2 \mu \mathrm{m}$ polyvinylidene fluoride (PVDF) syringe filter (GE Healthcare Life Sciences, Little Chalfont, United Kingdom) prior to injection into the LC-MS/MS system. All the solutions were stored at $4^{\circ} \mathrm{C}$, and were stable for at least 1 month.

\section{Preparation of tissue-spiked standard solution}

The tissue samples were prepared by slightly modifying a previously reported method (Yan et al. 2016). In brief, the bovine tissues were thawed first and the tissue slices $(2 \pm 0.02 \mathrm{~g})$ were collected into a $50 \mathrm{ml}$ centrifuge tube. The tissues in tube were homogenized with $1 \mathrm{ml}$ distilled water. Twenty $\mathrm{ng} / \mathrm{ml}$ of zilpaterol, ractopamine, clenbuterol and internal standards (zilpaterol D-7, clenbuterol D-9) which are used for quantitation were spiked into bovine tissues, and subsequently mixed and allowed to stand in a dark place for at least 20 min. Perchloric acid $(0.4 \mathrm{~N}, 20 \mathrm{ml})$ was added for protein precipitation and centrifuged at $10,000 \times \mathrm{g}$ for $15 \mathrm{~min}$. The collected supernatants were fixed at $\mathrm{pH} 12$ with $\mathrm{NaOH}$ and were extracted in ethyl acetate $(10 \mathrm{ml})$. Then, the drugs in ethyl acetate were evaporated under nitrogen at $40^{\circ} \mathrm{C}$. The final elute was reconstituted with $1 \mathrm{ml}$ of $0.01 \mathrm{~N} \mathrm{HCl}$ and filtrated with a $0.2 \mu \mathrm{m}$ polyvinylidene fluoride (PVDF) syringe filter (GE Healthcare Life Sciences, Little Chalfont, United Kingdom) for analysis by LC-MS/MS.

Method development and validation

A number of mixed organic/hydro-organic solvent systems as mobile phase were tried for the development of a suitable LC-MS/MS method for the simultaneous quantification of beta-agonists (zilpaterol, ractopamine 
and clenbuterol). Various variables were kept in mind while deciding the suitability of any solvent or mixture of solvents to be used as mobile phase such as the appropriateness for stability studies, sensitivity of the developed method, time consumed for the analysis, peak parameters, mutual miscibility of the constituent solvents, and the economy of the solvents. Based on the above criteria, various mobile phases in varying proportions were tried. Among the various solvents systems tried for LC-MS/MS quantification, a combination of $0.1 \%$ aqueous formic acid, and $0.1 \%$ formic acid in acetonitrile was selected with gradient flow for subsequent studies.

The developed method was validated based on the "Guideline for Residue Testing Laboratory". The document was referenced to EU Commission Decision 2002/657/EC (European Commission 2002). The linearity, recovery, limit of detection (LOD), limit of quantitation (LOQ), and coefficient of variation (CV) of the method were determined for each of the drug components from both the standard solutions and tissue-spiked standard solutions. The results for accuracy and precision were expressed as the percentage of recovery and the coefficient of variation $(\mathrm{CV})$. The LOD and LOQ were calculated from the standard deviation of responses and the slope obtained from the calibration curve as stated by the following equations (Hossain at el. 2017):

$\mathrm{LOD}=(3.3 \times \mathrm{SD}) /$ slope

$\mathrm{LOQ}=(10 \times \mathrm{SD}) /$ slope

Calibration curves were obtained relating relative responses of the analyte (analyte response at different concentrations versus the internal standard response) versus nominal concentrations added to the analyst at different levels. In all cases, standards, reagent blanks, matrix blanks and spiked-matrix control samples were analyzed in the same series.

Application of the method

The developed method was applied to 50 domestic and 50 imported bovine samples for determining the content of drug residues. The preparation process of these tissue samples is the same as mentioned above in the "Preparation of tissue-spiked standard solution" section. Additional drug components were not supplemented with the tested bovine samples.

\section{Development of the method}

\section{Results}

In the LC-MS/MS chromatogram (Plate IV, Fig. 2), peaks of pure compounds of zilpaterol, ractopamine, and clenbuterol were observed at the retention times between 2.33 and $3.44 \mathrm{~min}$. When the tissue-spiked zilpaterol, ractopamine, and clenbuterol solutions were injected into the LC-MS/MS systems, the retention times and the mass to charge values $(\mathrm{m} / \mathrm{z})$ of these $\beta$-agonist residues present in tissues were found to be the same as in the solution of pure compounds.

\section{Validation of the method}

The LOD and LOQ were $0.4 \mathrm{ng} / \mathrm{g}$ and $1.3 \mathrm{ng} / \mathrm{g}$ for zilpaterol;1.7 ng/g and $5.0 \mathrm{ng} / \mathrm{g}$ for ractopamine, and $0.5 \mathrm{ng} / \mathrm{g}$ and $1.7 \mathrm{ng} / \mathrm{g}$ for clenbuterol, respectively (Table 2). The correlation coefficients of zilpaterol, ractopamine and clenbuterol were 0.99 ; the recovery rates of zilpaterol, ractopamine and clenbuterol as shown in Table 2, were determined by comparing the mean of peak intensities and peak areas of tissue spiked samples with the standard solution. The mean recovery of zilpaterol in the tissue matrix was $99 \%(\mathrm{w} / \mathrm{v})$ when the tissue was spiked with pure zilpaterol. The mean recoveries of ractopamine and clenbuterol were $74 \%$ and $102 \%$ (w/v), respectively, in tissues spiked with pure ractopamine and clenbuterol (Table 2). The LOD and LOQ of these three beta-agonists ranged from $0.4-1.7$, and $1.3-5.0 \mathrm{ng} / \mathrm{g}$, respectively. The percentages of coefficients of variations were $1.9,9.4$, and $3.9 \%$ for zilpaterol, ractopamine, and clenbuterol, respectively. The chromatograms of spiked bovine tissue samples, obtained in the MRM mode are shown in Fig. 2, which indicate the retention times and peak intensities.

\section{Monitoring of $3 \beta$-agonists in veterinary samples}

The screening results of these $3 \beta$-agonists in bovine samples are summarized in Table 3 . None of these $3 \beta$-agonists were detected from 50 bovine liver samples of domestic sources. Conversely, zilpaterol was detected from one sample of imported bovine meat at a level of $6.3 \mathrm{ng} / \mathrm{g}$, as shown in Table 3 . 
Table 2. Analytical method validation indices of three $\beta$-agonists in spiked bovine tissue samples.

\begin{tabular}{lccccc}
\hline Compound & $\begin{array}{c}\text { Correlation } \\
\text { coefficient (R2) }\end{array}$ & $\begin{array}{c}\text { Average } \\
\text { recovery (\%) }\end{array}$ & CV (\%) & $\begin{array}{c}\text { LOD } \\
(\mathrm{ng} / \mathrm{g})\end{array}$ & $\begin{array}{c}\text { LOQ } \\
(\mathrm{ng} / \mathrm{g})\end{array}$ \\
\hline Zilpaterol & 0.99 & 99 & 1.9 & 0.4 & 1.3 \\
Ractopamine & 0.99 & 74 & 9.4 & 1.7 & 5.0 \\
Clenbuterol & 0.99 & 102 & 3.9 & 0.5 & 1.7 \\
\hline
\end{tabular}

$\mathrm{CV}$ - coefficient of variation; LOD - limit of detection; LOQ - limit of quantitation.

Table 3. Test results of $\beta$-agonists in incurred bovine tissue samples.

\begin{tabular}{lcccc}
\hline Samples & Number tested & $\begin{array}{c}\text { Detected } \\
\text { compounds }\end{array}$ & $\begin{array}{c}\text { Number } \\
\text { detected }\end{array}$ & $\begin{array}{c}\text { Concentration } \\
(\mathrm{ng} / \mathrm{g})\end{array}$ \\
\hline Bovine liver (domestic) & 50 & $\begin{array}{c}\text { Zilpaterol } \\
\text { Ractopamine }\end{array}$ & - & - \\
& & Clenbuterol & - & - \\
Bovine meat (imported) & 50 & Zilpaterol & 1 & 6.3 \\
& & Ractopamine & - & - \\
\hline
\end{tabular}

\section{Discussion}

In the current study, we developed the LC-MS/MS method in order to identify and quantify zilpaterol, ractopamine, and clenbuterol simultaneously from bovine tissues. Generally, it requires several trials to select a suitable mobile phase for developing a method, because of the complexity of the chemical compounds in biological samples, and the affinities of the components toward various solvents. The proportions of the organic and aqueous phases were adjusted to obtain a simple assay method with a reasonable and suitable retention time, and sharp peak. The instruments under the optimized conditions gave well-resolved symmetric band for zilpaterol, ractopamine, and clenbuterol from the solutions of pure compounds as well as from the bovine tissues.

A fast, simple, and efficient extraction procedure was one of the essential parts of the quantification method in the present study. The extraction procedure was a modification of the one described by Yan et al. (2016), for the screening of $\beta$-agonists in bovine liver by HPLC. However, in the present study, the totality of tissue supernatant was dried by nitrogen evaporation to increase the signal of these $3 \beta$-agonists, and the detection system was changed to MS/MS. The extraction of $\beta$-agonists from meat and other tissues has usually been accomplished by SPE using different reversed-phase adsorbents (Liu et al. 2011), but it was indicated in several studies that SPE to separate clenbuterol and other $\beta$-agonists from bovine liver resulted in low extraction efficiency.

The chromatographic method that has been published for the extraction and determination of $\beta$-agonists in liver using large volumes of solvents is expensive (Liu et al. 2011). Meanwhile, compared to gas chromatography (GC) methods that are used for the determination of $\beta$-adrenergics, the major advantages of the present method were the short extraction time and no need of a derivatization step. Therefore, the procedure described here enables the direct extraction of $\beta$-agonists without complementary purification steps.

The specificity of the analytical method ensures that the signals measured come from the desired compounds, and there is no interference from the diluents, matrix components, and 
mobile phase. The LC-MS/MS detection also supported the specificity of the method and provided evidence for the homogeneity of the peaks of analytes (Plate IV, Fig. 2). Peaks obtained from recovery experiments were checked for uniformity using the mass spectrum. These spectra were superimposed whenever overlaid; showing that there was no other coeluting peaks, in every instance for each of the analytes. The data obtained in the validation study proved that the proposed method is validated and can be used for the determination and quantification of zilpaterol, ractopamine, and clenbuterol.

According to the International Conference on Harmonization (ICH) guideline (International Conference on Harmonization 1996), there are several approaches to determine the LOD and LOQ. Visual evaluation, signal to noise ratio, and the use of standard deviation (SD) of the response and the slope of the calibration curve are the generally used methods. The Codex Alimentarius Commission recommends maximum residue limits (MRLs) of zilpaterol hydrochloride for cattle of $0.5 \mathrm{ng} / \mathrm{g}$ in muscle, $3.5 \mathrm{ng} / \mathrm{g}$ in liver, and $3.3 \mathrm{ng} / \mathrm{g}$ in kidney. The recommended MRLs of ractopamine hydrochloride for cattle and pigs of $10.0 \mathrm{ng} / \mathrm{g}$ in muscle and fat, $40 \mathrm{ng} / \mathrm{g}$ in liver and $90 \mathrm{ng} / \mathrm{g}$ in kidney (Codex Alimentarius Commission 2015). According to the previously published article, the acceptable MRLs of clenbuterol for cattle are $0.2 \mathrm{ng} / \mathrm{g}$ in muscle and fat, $0.6 \mathrm{ng} / \mathrm{g}$ in liver and kidney, and $0.05 \mathrm{ng} / \mathrm{ml}$ for cattle milk, expressed as parent drug (Morales-Trejo et al. 2013). Thus, the achieved signal intensities of the developed method are sufficient to determine the drug residues in bovine tissues.

Linearity is the ability of a method to produce test results that are directly proportional to the concentrations of the analyte within a given range. Linear responses have established from the concentration verses response curve of each compound on the basis of five standards covering the concentration range of 0 to $500 \mathrm{ng} / \mathrm{ml}$. The acceptance criterion for linearity is that the correlation coefficient $\left(\mathrm{r}^{2}\right)$ should not be $<0.990$ for the least squares method of the analysis of the line (OMCL Network/EDQM of the Council of Europe 2005). This result demonstrates the linearity of this method over a wide dynamic range. The linearity was good for all analytes in the wide range of tested concentrations $(0,5,50$, $100,500 \mathrm{ng} / \mathrm{ml})$ as proved by the correlation coefficients $\left(\mathrm{r}^{2}\right)$ which were higher than 0.99 for all curves.

The recovery percentage of ractopamine was quite lower, which could be attributable to the interference of the sample matrix or the slowness of extraction of those compounds from the extract matrix. Moreover, the low recovery is justified in this case, as the expected recovery is dependent on the percentage of the analyte in the matrix (Association of Analytical Chemists 2011), indicating that the analytical method is validated. So, the current LC-MS/MS method provides a sensitive and reliable procedure for the determination of $3 \beta$-agonists in bovine tissues. The simple extraction procedure requires a very short time but with acceptable sample recoveries, making the method suitable for real-time and fieldready analysis.

The proposed LC-MS/MS method was further utilized to screen the $3 \beta$-agonists in the real samples including 50 domestic bovine liver samples and 50 imported bovine meat samples which were taken by provisional veterinary services as part of the National Residue Programme (NRP) for veterinary drug residue surveillance. These results demonstrated first the efficiency of the proposed analytical methodology for zilpaterol, ractopamine and clenbuterol residue identification in edible tissues, and secondly the suitability of particular matrixes for the control of the illegal use of these compounds. These results suggested that zilpaterol was still being illegally used in food-producing animals in some countries.

In conclusion, a suitable detection method of $\beta$-agonists in the livestock samples is required by LC-MS/MS that allows a fast, easy and sensitive multi-residue analysis in order to prevent the use of these $\beta$-agonists as feed additives, and to manage the appropriate and efficient therapeutic use of them. Based on the validation of this method, it serves as an 
accurate and reliable method for the identification and quantification of these $\beta$-agonists' residue in bovine tissues. The simplicity of this method in the extraction of drugs from sample matrixes allows one to easily detect and quantify these $\beta$-agonists in bovine tissues by LC-MS/MS. Compared to other extraction methods, it also saves reagents used. In view of this, the proposed method could be adopted for quality control and routine analysis.

\section{Acknowledgements}

This study was supported by the Veterinary Science Research Project Grant No. B-1543073-2015-17-0102 from the Animal and Plant Quarantine Agency, Republic of Korea.

\section{References}

Anderson DB, Moody DE, Hancock DL 2009: Beta adrenergic agonists. Marcel Dekker Inc., New York, pp 104-107

Angeletti R, Oriundi MP, Piro R, Bagnati R 1993: Application of an enzyme-linked immunosorbent assay kit for $\beta$-agonist screening of bovine urines in north-eastern Italy. Anal Chim Acta 275: 215-219

Antignac JP, Marchand P, Le Bizec B, Andre F 2002: Identification of ractopamine residues in tissue and urine samples at ultra-trace level using liquid chromatography-positive electrospray tandem mass spectrometry. J Chromatogr B 774: 59-66

Association of Analytical Chemists (AOAC): Standard Format and Guidance for AOAC Standard Method Performance Requirement. Available from: http://www.aoac.org/imis15_prod/AOAC_Docs/ISPAM/3.5SMP RGuidelinev12.1.pdf. Last modified January 31, 2011. Accessed January 25, 2017

Batjoens P, Courtheyn D, De Brabander HF, Vercammen J, Wasch KD, Logghe M 1996: Gas chromatographictandem mass spectrometric analysis of clenbuterol residues in feces. J Chromatogr A 750: 133-139

Blomgren A, Berggren C, Holmberg A, Larsson F, Sellergren B, Ensing K 2002: Extraction of clenbuterol from calf urine using a molecularly imprinted polymer followed by quantitation by high-performance liquid chromatography with UV detection. J Chromatogr A 975: 157-164

Bocca B, Di Mattia M, Cartoni C, Fiori M, Felli M, Neri B, Brambilla G 2003: Extraction, clean-up and gas chromatography-mass spectrometry characterization of zilpaterol as feed additive in fattening cattle. J Chromatogr B783: 141-149

Codex Alimentarius Commission: Maximum Residue Limits for Veterinary Drugs in Foods: Updated as at the $38^{\text {th }}$ session of the Codex Alimentarius Commission. Available from: http://www.google.co.kr/url?sa=t\&rct=j\&q $=\&$ esrc $=\mathrm{s} \& \mathrm{frm}=1 \&$ source $=$ web $\& \mathrm{~cd}=1 \& \mathrm{cad}=$ rja \&uact $=8 \& \mathrm{ved}=0 \mathrm{ahUKEwiXhc3}$ sourNAhUFtxQKHQ2FBQ4 QFggaMAA\&url=http\%3A\%2F\%2Fwww.fao.org\%2Finput\%2Fdownload\%2Fstandards\%2F45\%2FMRL2 2015e.pdf\&usg=AFQjCNHD3OTpb8bXyCT_H2gxBkZe6idcUQ\&bvm=bv.126130881,d.bGg. Last modified July 23, 2015. Accessed January 25, 2017

Degand G, Bernes-Duyckaerts A, Delahaut P, Maghuin-Rogister G 1993: Determination of $\beta$-agonists in urine by enzyme immunoassay based on the use of an anti-salbutamol antiserum. Anal Chim Acta 275: 241-247

European Commission: Concerning the Performance of Analytical Methods and the Interpretation of Results. Available from: http://eur-lex.europa.eu/legal-content/EN/TXT/PDF/?uri=CELEX:32002D0657\&from=EN. Last modified august 17, 2002. Accessed January 25, 2017

European Commission: On Measures to Monitor Certain Substances and Residues Thereof in Live Animals and Animal Products and Repealing. Available at: www.eur-lex.europa.eu/legal-content/EN/TXT/PDF/?uri=CEL EX:31996L0023\&from=EN. Last modified May 23, 1996. Accessed January 25, 2017

Hossain MA, Park HC, Jeong KH, Jang YH, Kim DG, Kang JW, Lee KJ 2017: Pharmacokinetic and pharmacodynamic evaluation of marbofloxacin in pig against Korean local isolates of Actinobacillus pleuropneumoniae. BioMed Res Int 2017: 1-11

International Conference on Harmonization (ICH): Validation of Analytical Procedures: Methodology of Technical Requirements for Registration of Pharmaceuticals for Human Use. Available from: http://www.fda. gov/downloads/drugs/guidancecomplianceregulatoryinformation/guidances/ucm073384.pdf. Last modified November 29, 1996. Accessed January 25, 2017

Kulikovskii AV, Lisitsyn AB, Gorlov IF, Slozhenkina MI, Savchuk SA 2016: Determination of growth hormones ( $\beta$-agonists) in muscle tissue by HPLC with mass spectrometric detection. J Anal Chem 71: 1052-1056

Liu B, Yan H, Qiao F, Geng Y 2011: Determination of clenbuterol in porcine tissues using solid-phase extraction combined with ultrasound-assisted dispersive liquid-liquid microextraction and HPLC-UV detection. J Chromatogr B 879: 90-94

Martinez-Navarro JF 1990: Food poisoning related to consumption of illicit $\beta$-agonist in liver. Lancet 336: 1311 Morales-Trejo F, León SVY, Escobar-Medina A, Gutiérrez-Tolentino R 2013: Application of high-performance 
liquid chromatography-UV detection to quantification of clenbuterol in bovine liver samples. J Food Drug Anal 21: 414-420

OMCL Network/EDQM of the Council of Europe: Validation of Analytical Procedures PA/PH/OMCL (05) 47 DEF. Available from: http://www.blue-inspection.com/gxp/00_EDQM_USP_Nat_Bodies/Validation_of_ Analytical_Procedures.pdf. Last modified June 15, 2005. Accessed January 25,2017

Wang L, Zeng Z, Wang X, Yang J, Chen Z, He L 2013: Multiresidue analysis of nine $\beta$-agonists in animal muscles by LC-MS/MS based on a new polymer cartridge for sample cleanup. J Sep Sci 36: 1843-1852

Yan K, Zhang H, Hui W, Zhu H, Li X, Zhong F, Chen C 2016: Rapid screening of toxic salbutamol, ractopamine, and clenbuterol in pork sample by high performance liquid chromatography-UV method. J Food Drug Anal 24: $277-283$ 
Plate IV

Jeong K. et al.: Simultaneous determination ... pp. 47-54

BAGS 20110524-008
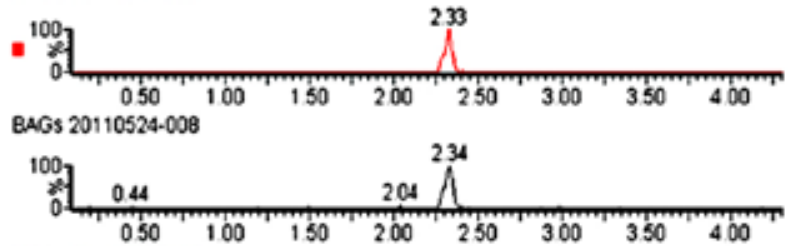<smiles>C[Ge]1CCCO1</smiles><smiles>C1=C[C@H]2C=C[C@H]1O2</smiles>

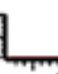

PAGS 20110524-008

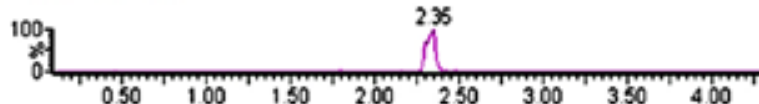

BAGS 20110524-008

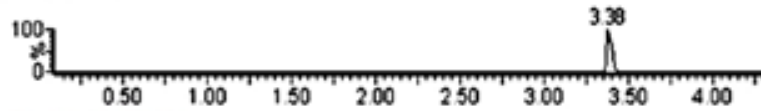

BAGs 20110524-008

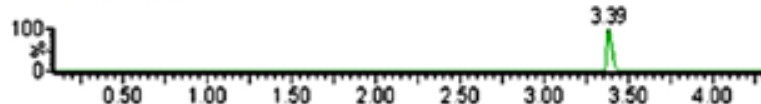

BAGs 20110524-008

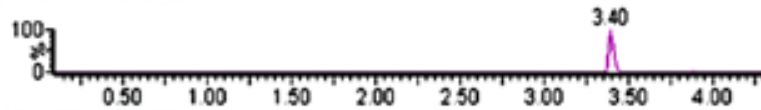

BAGS 20110524-008

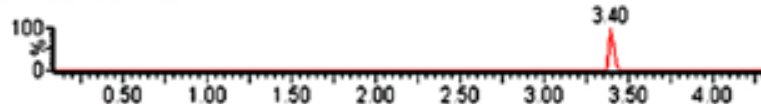

BAGs $20110524-008$

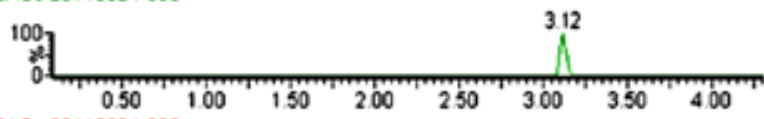

BAGs 20110524-008

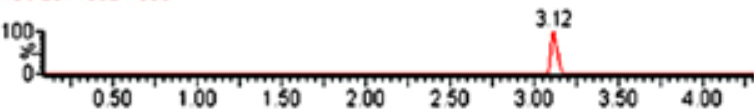

BAGS 20110524-008

5. MRM of 2 Channels ES+ $269.16>251.14$ (Zipaterol-d7 2278

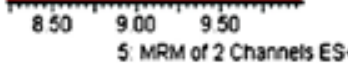

$251.14>185$ (Zlpaterol-d?

9.02

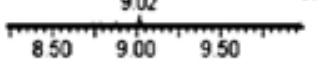

4. MRM of 2 Channets ES* $262.1>244.17$ (Zlpaterol $161 \mathrm{e}$
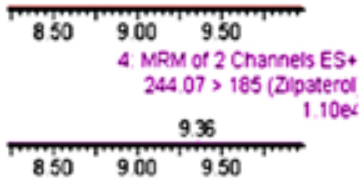

3 MRM of 2 Channets ES+ $286.1>268.06$ (Clenbuterol-d9 2910

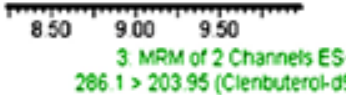
$390 \mathrm{e}$

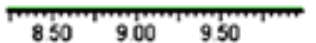

2 MRM of 2 Channels ES+ $277>259$ (Clenbuterol $289 \mathrm{e}$

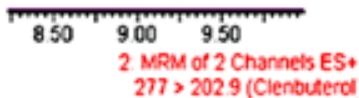
$390 \mathrm{e}$

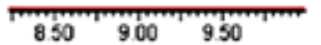

1. MRM of 2 Channels ES+ $302.1>164$ (Ractopamine $312 \mathrm{e}$

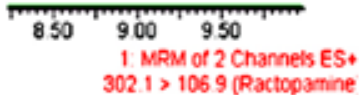
2 ooes

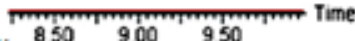

Fig. 2. Liquid chromatography-tandem mass spectrometry (LC-MS/MS) chromatograms in multiple reaction monitoring (MRM) acquisition mode of $3 \beta$-agonists (zilpaterol, ractopamine, and clenbuterol) and 2 internal standards (zilpaterol D-7, clenbuterol D-9) spiked at a concentration of $20 \mathrm{ng} / \mathrm{ml}$ in liver tissue. 